\title{
Fatigue of Additive Manufacturing Specimens: A Comparison with Casting Processes ${ }^{+}$
}

\author{
Eric Charkaluk ${ }^{1, *}$ and Victor Chastand ${ }^{2}$ \\ 1 Laboratoire de Mécanique des Solides, CNRS, Ecole Polytechnique, 91128 Palaiseau, France \\ 2 Thales Global Services, 78140 Vélizy-Villacoublay, France; victor.chastand@thalesgroup.com \\ * Correspondance: eric.charkaluk@polytechnique.edu; Tel.: +33-1-6933-5795 \\ + Presented at the 18th International Conference on Experimental Mechanics (ICEM18), Brussels, Belgium, \\ 1-5 July 2018.
}

Published: 14 June 2018

\begin{abstract}
In this paper, the specificity and/or the common features of materials coming from such new additive manufacturing processes will be compared to more classical one, like casting process. Fatigue properties of Ti-6Al-4V specimens built by EBM and SLM are first compared depending on several process parameters. Then, at the microstructure scale, it is shown that surface defects and unmelted zones seem to be the dominant features. It will be shown that similarities can then be drawn with casting processes where shrinkage and pores are also associated to damage mechanisms.
\end{abstract}

Keywords: additive manufacturing; fatigue; damage mechanisms

\section{Introduction}

With the fast development of additive manufacturing processes for metallic materials-powder bed or direct powder projection with laser or electron beam energy sources, for instance-the question of the optimal structure design can now be freely addressed, as practically all seems possible to manufacture. The next question is then: optimal regarding what? One of the important questions which has to be addressed is the durability of these structures regarding, for example, fatigue and/or fracture phenomena, as these structures will be used in many industrial domains (energy, aeronautics, aerospace, ground transportation ...). Recent papers addressed this aspect, evaluating the effect of process parameters on fatigue lifetimes [1,2]. Following these works, fatigue properties of Ti-6Al-4V specimens built by EBM and SLM are first compared in this communication. Several parameters are assessed: processes, manufacturing direction, surface roughness, HIP treatment. Fatigue properties are analysed in relation with the crack initiation mechanisms identified on each specimen's post-mortem micrographs. The results show that machined specimens have better fatigue properties as surface defects are removed. HIP treatment improves fatigue properties by decreasing the defects size. Small differences in lifetime are observed between horizontal and vertical building directions because of different defect shapes regarding the loading axis. Finally, EBM and SLM parts have approximately the same fatigue properties, which are equivalent to conventional casting processes [3].

However, in most of the recent studies, there is a lack of analysis in terms of fatigue damage mechanisms, in particular crack initiation. Therefore, in a second part, the type of defect conducting to crack initiation is studied in the case of these Ti-6Al-4V specimens. At the microstructure scale, it is shown that surface defects and unmelted zones seem to be the dominant features. As this type of defect is close to casting ones, these fatigue crack initiation processes are then compared and discussed with the ones identified in specimens obtained from casting processes [4-6]. In these previous studies, the main interest was the possibility to observe, qualify and quantify on in-situ 
tests, the three dimensional mechanisms responsible of the crack initiation and the microcrack growth. Then, it will be shown that similarities can be drawn.

\section{Materials and Methods}

The fatigue test specimens used in this communication are made of pre-alloyed powder of Ti-6Al-4V and were processed using SLM and EBM. The SLM specimens were built on a SLM 250HL machine with a layer thickness of $50 \mu \mathrm{m}$. These specimens were stress relieved at $640{ }^{\circ} \mathrm{C}$ for $4 \mathrm{~h}$. The EBM specimens were built on an Arcam A2 machine, also with a layer thickness of $50 \mu \mathrm{m}$ but they were not stress relieved as the EBM machine room is maintained at $680^{\circ} \mathrm{C}$. It is largely accepted that residual stresses are negligible in this case. 96 cylindrical specimens (length: $64 \mathrm{~mm}$ gauge diameter: $4 \mathrm{~mm}$, threaded head) were built in total, 12 specimens for each parameter as shown in Table 1. 12 specimens for each process had their surface left as-built. Roughness has not been measured on each of these fatigue specimens but on specimens obtained in the same condition. For SLM, the typical arithmetic roughness was found to be $15-25 \mu \mathrm{m}$ whereas it is $20-35 \mu \mathrm{m}$ for EBM. The others were machined and then polished by tribofinishing leading to a surface roughness $\mathrm{Ra} \leq 0.2 \mathrm{~mm}$. 12 specimens for each process were treated with a HIP treatment at $920^{\circ} \mathrm{C}$ under 1020 bar for $2 \mathrm{~h}$. All details are given in [7].

As shown in [1,2], typical defects observed in a Ti-6Al-4V alloy manufactured by a powder-bed additive manufacturing process are: (i) the as-built roughness of the surface, which can also be associated to surface defects (unmelted zone on surface, open porosities), (ii) internal unmelted zones, (iii) internal porosities, generally smaller than the unmelted zones as associated to untrapped gases.

Table 1. List of Ti6Al4V fatigue tested specimens.

\begin{tabular}{ccccc}
\hline Process & Manufact. Direction & Number of Specimens & Thermal Treatment & Surface Finishing \\
\hline \multirow{4}{*}{ SLM } & $\mathrm{Z}$ & 12 & $640^{\circ} \mathrm{C} / 4 \mathrm{~h}$ & Polishing \\
& $\mathrm{X}-\mathrm{Y}$ & 12 & $640^{\circ} \mathrm{C} / 4 \mathrm{~h}$ & Polishing \\
& $\mathrm{Z}$ & 12 & $640^{\circ} \mathrm{C} / 4 \mathrm{~h}$ & None \\
& $\mathrm{Z}$ & 12 & $640^{\circ} \mathrm{C} / 4 \mathrm{~h}+\mathrm{HIP}$ & Polishing \\
\hline \multirow{3}{*}{ EBM } & $\mathrm{Z}$ & 12 & None & Polishing \\
& $\mathrm{X}-\mathrm{Y}$ & 12 & None & Polishing \\
& $\mathrm{Z}$ & 12 & None & None \\
& $\mathrm{Z}$ & 12 & HIP & Polishing \\
\hline
\end{tabular}

High cycle uniaxial fatigue tests were performed with pure reversed stress controlled loading applied with a constant stress amplitude and a loading ratio $R=-1$. An Amsler vibrophore was used with a frequency between 85 and $96 \mathrm{~Hz}$. Some specimens were loaded with stress amplitude above $700 \mathrm{MPa}$. In these cases, the frequency was decreased to $20 \mathrm{~Hz}$ to prevent the specimens from self-heating. The fatigue tests were conducted until the failure of the specimen or when attaining $10^{7}$ cycles. After the tests, the crack initiation area was analyzed regarding post-mortem micrographs systematically performed on all broken specimens using a Nachet Vision optical microscope and also a Hitachi S-3600N scanning electronic microscope.

\section{Fatigue Lifetimes}

In this part, the fatigue test results obtained with the different parameters are presented in classical S-N curves form. In the S-N curves, all the stresses shown are divided by the same constant value in order to get relative ones, permitting however systematic analysis and comparisons between parameters and/or processes. The maximal stress is chosen in order to allow comparisons with [8]. All these results are compared in Figure 1 to tendencies extracted from [8] obtained by casting and wrought processes and for which load ratio is not precise. The results from reference [8] were placed in this normalized graph by dividing them also by the same constant as for the other $\mathrm{S}-\mathrm{N}$ curves. This figure enables to summarize all the results and observations and one could 
underline that: (i) machining and polishing improve the fatigue properties, i.e., the stress amplitude for $10^{7}$ number of cycles, of about $100 \%$, (ii) performing an HIP treatment improves again the fatigue properties of about $80 \%$, (iii) the effect of the manufacturing direction is more difficult to observe, but $X Y$ specimens seem to have slightly better fatigue properties than $Z$ specimens and (iv) after surface polishing, fatigue properties are at the same level of those obtained for a classical casting process and even wrought samples after HIP treatment. The last important conclusion is that no major effect of the additive manufacturing process (EBM versus SLM) can be observed in all these results: whatever the condition (as-built, machining, $Z$ or XY and HIP), specimens obtained by EBM and SLM have similar lifetimes, regarding the scatter associated to the experimental results. All these results are detailed in Chastand et al. [3] and in [7].

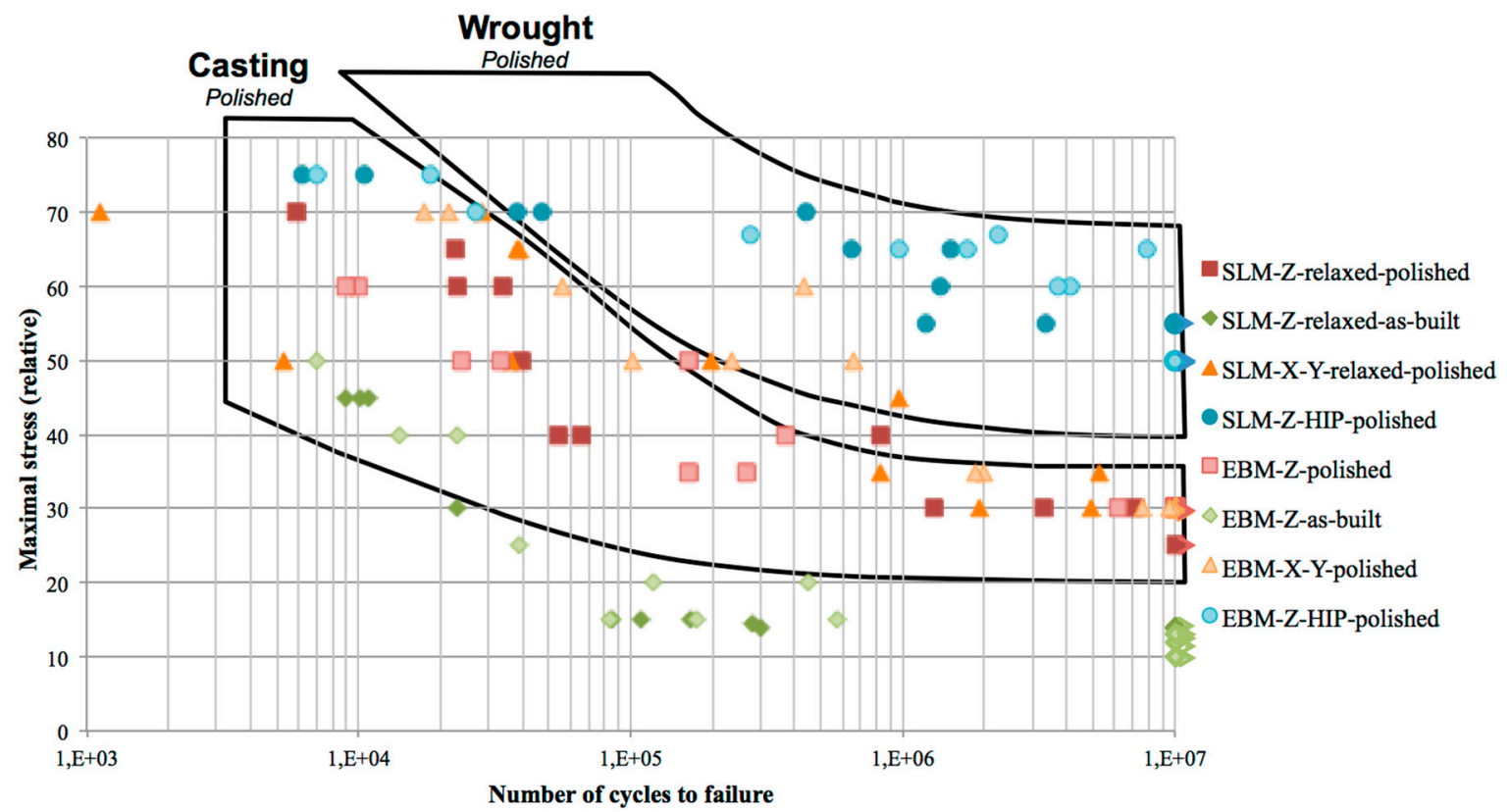

Figure 1. Comparison of fatigue lifetime obtained for both SLM and EBM processes with more classical casting and wrought processes (tendencies extracted from [8]).

\section{Damage Mechanisms}

\subsection{Observations on Ti6Al4V Specimens}

After the tests, crack initiation areas were analysed regarding post-mortem micrographs systematically performed on all broken specimens. Different types of defects were identified to be at the origin of crack initiations and are shown in Figure 2. These defects are similar to those presented in [2]. Figure 2a,b corresponds to small internal defects, i.e., residual small porosities, residual small unmelted zones after HIP treatment (Figure 2a) or $\alpha$-phase (Figure 2b) as shown in [2]. Internal unmelted zones, as observed in Figure $2 \mathrm{c}, \mathrm{d}$ are typical to these powder-bed processes. The orientations of these unmelted zones are parallel to the layers. Then, depending on the building directions, these unmelted zones can be parallel (see Figure 2d) or perpendicular (see Figure 2e) to the loading direction. Cracks can also initiate from the surface, due: (i) to the initial as-built roughness or (ii) from initially sub-surface defects, which intersect the surface after the machining and polishing steps. All the broken specimens surfaces were observed and analysed and the crack initiation associated defects were determined following the previous classification (surface, internal un- melted zones, small internal defects). Results are synthesized in Figure 3 where each type of defect conducting to crack initiation has been associated to a specific symbol. One can clearly distinguish three main domains: (i) shorter lifetime are mainly associated to crack initiations on surface defects, (ii) intermediate lifetime to internal unmelted zone and (iii) longer lifetime to small internal defects, even if a relative scatter is observed. 

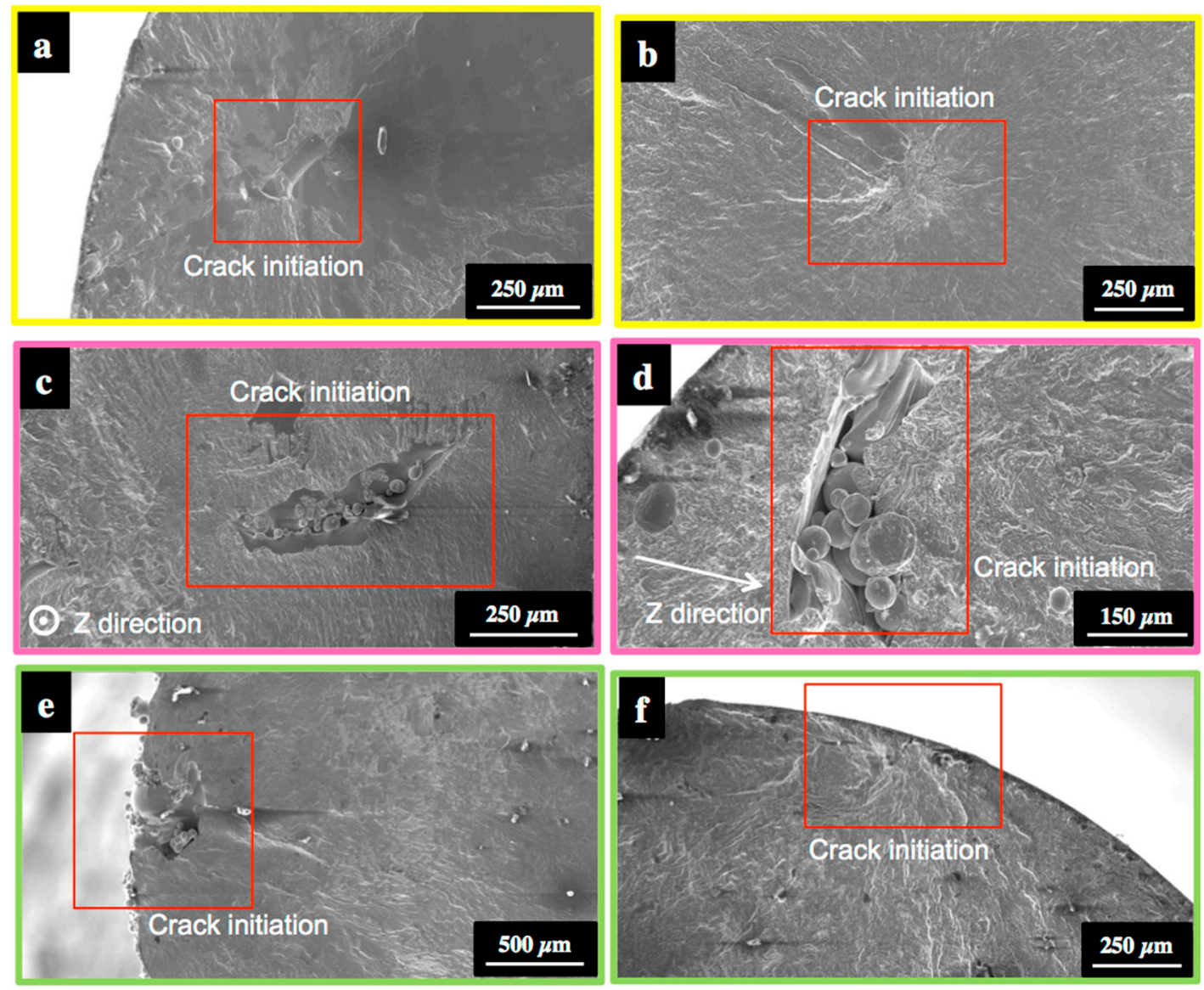

Figure 2. Different types of defects identified to be the crack initiation origin: porosities on (a) EBM Z polished $\sigma_{\max }=50, N_{R}=163,000$ and (b) EBM Z HIP polished $\sigma_{\max }=65, N_{R}=1,721,160$, lack of fusion zones on (c) SLM Z polished $\sigma_{\max }=30, \mathrm{~N}_{\mathrm{R}}=7,128,212$ and (d) EBM XY polished $\sigma_{\max }=30, \mathrm{~N}_{\mathrm{R}}=$ 9,610,224 and surface defects on (e) SLM Z as-built $\sigma_{\max }=14,5, N_{R}=278,380$ and (f) EBM Z HIP polished $\sigma_{\max }=60, \mathrm{~N}_{\mathrm{R}}=412,3148$.

\subsection{Discussion and Comparison with Casting Processes}

Despite the relative scatter observed in Figure 3, it is observed that as-built specimens, which posses the highest roughness, generally conduct to the shorter lifetimes domain with a crack initiating from the surface. This is a common observation in fatigue that cracks initiate generally from the surface. But this conclusion must be relativized when sub-surface or internal defects (as porosities or unmelted zones) are present as in the present case or also in the case of casting process (as porosities or shrinkages) [6]. Therefore, when machining and polishing as-built specimens, surface defects are mostly removed. As they are the most critical defects, lifetimes are generally larger than for as-built specimens as already shown in $[1,9,10]$. However, one can also observed in Figure 3 machining and polishing specimens with shorter lifetimes. In fact, surface machining can conduct to the emergence of initially internal defects (porosities and/or unmelted zones) on the surface, which increases their criticality. 


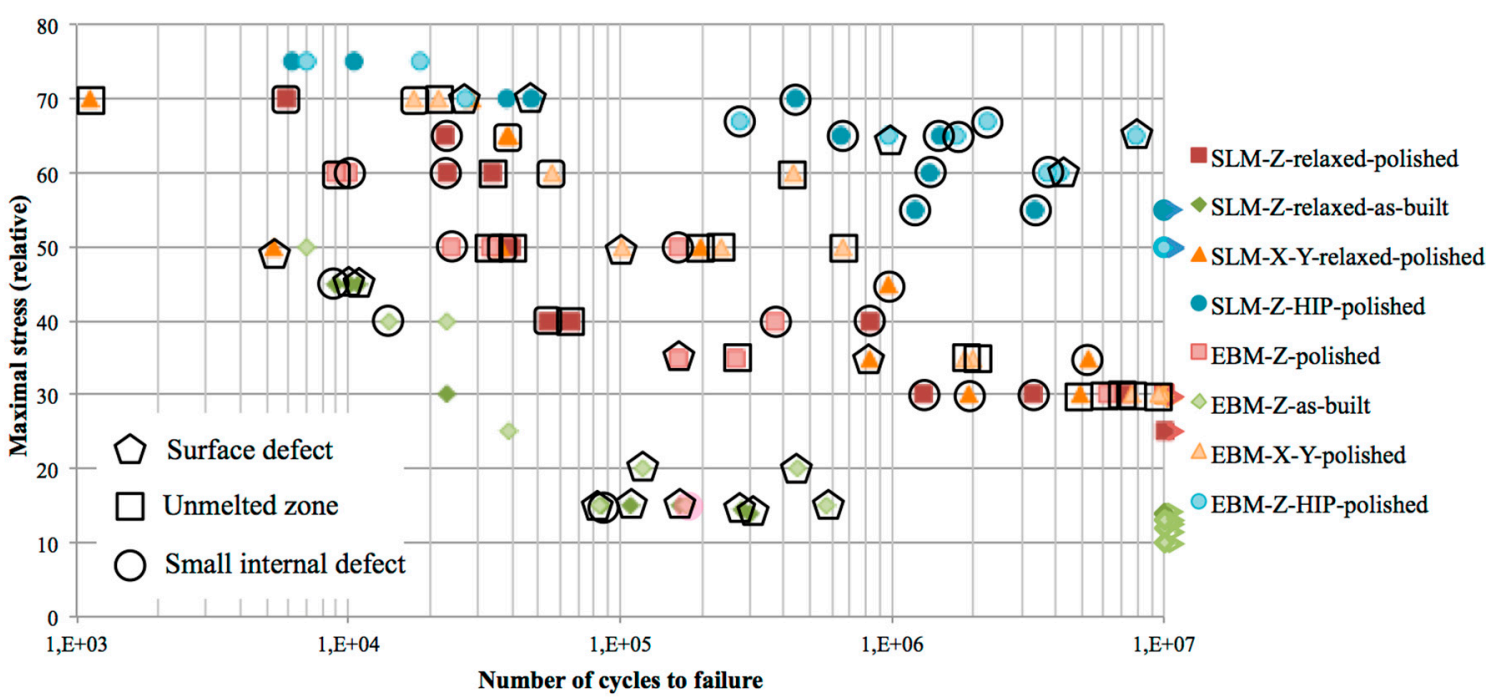

Figure 3. Influence of the defects on the lifetimes obtained for both EBM and SLM processes.

But beyond such particular cases, the intermediate domain in Figure 3 corresponds mainly to crack initiation on unmelted zones as soon as the specimens are machined and polished. Such unmelted zones are observed in the bulk or in sub-surface areas. As the position of the defects respectively to the surface is an influencing parameter on the crack initiation time, as shown in the case of shrinkage in casting alloys [4,5], this has an impact on the criticality and the lifetimes. In the case of unmelted zones, one can observe in Figure 3 that the fatigue properties are qualitatively slightly better for the specimens built in the XY direction. Indeed, as unmelted zones preferably appear between two layers, the orientation of such defect is mainly perpendicular to the building direction. Then, for the specimens built in the $X Y$ direction, unmelted zones are certainly mainly parallel to the loading direction, which is qualitatively less critical than to be perpendicular to the loading direction in the case of the $\mathrm{Z}$ building direction. This could explain the observed difference in fatigue properties between $X Y$ and Z-building directions but unfortunately, this assumption has not been confirmed by experimental observations. Finally, the last domain with the longer lifetimes corresponds mostly to HIP specimens, as HIP is known to reduce the size of most of the defects (porosities or unmelted zones).

However, in this study, as in other ones as [1], only post-mortem observations were conducted and no quantification of defects size and/or morphology were done, which could improve the proposed qualitative analysis. In fact, in the case of casting alloys, it has been shown that a simple 2D analysis (size, morphology) from data extracted from surface images of such complex 3D defects is generally not sufficient to understand and quantify their impact on crack initiation mechanisms and on lifetime, even if some statistical corrections are possible [11]. Therefore, a systematic 3D quantitative analysis of the specimens microstructure by CT-tomography (as conducted in [6]) could be a direct perspective of this work, associated to in-situ fatigue tests as in $[4,5]$.

\section{Conclusions}

In summary, fatigue tests have been performed on additive manufactured specimens with two powder bed fusion processes (EBM and SLM). The effects of manufacturing direction, HIP treatment and roughness have been observed and analysed according to micrographs performed on each broken specimen. Three types of defects have been observed and could be sorted from the most to the less critical: surface defects, unmelted zones and small internal defects. Machining and polishing steps improve the fatigue properties by removing surface defects and initial roughness. HIP treatment improves fatigue by decreasing the defects size. The effect of the manufacturing direction depends on the presence of unmelted zones. Finally, the effect of the process-EBM and SLM-seems to be negligible because defects are of the same type in both cases. Depending on the post-treatment applied to the specimens, parts coming from additive manufacturing with these both 
processes show similar fatigue properties than cast or wrought parts. The qualitative conclusions about crack initiation mechanisms could be challenged by performing 3D CT-tomography associated to in situ tensile tests on several specimens; real-time analysis could then be performed in order to observe the crack initiation and propagation phenomenon as alreadydone on casting alloys [4-6].

Author Contributions: V.C. conducted the experimental studies and V.C. and E.C. analysed the data and wrote the paper.

Acknowledgments: The authors acknowledge Philippe Quaegebeur and Wilson Maia for their fruitful discussion during this study.

Conflicts of Interest: The authors declare no conflict of interest.

\section{References}

1. Bagehorn, S.; Wehr, J.; Maier, H.J. Application of mechanical surface finishing processes for roughness reduction and fatigue improvement of additively manufactured Ti-6Al-4V parts. Int. J. Fatigue 2017, 102, $135-142$.

2. Günther, J.; Krewerth, D.; Lippmann, T.; Leuders, S.; Tröster, T.; Weidner, A.; Biermann, H.; Niendorf, T. Fatigue life of additively manufactured Ti-6Al-4V in the very high cycle fatigue regime. Int. J. Fatigue 2017, 94, 236-245.

3. Chastand, V.; Quaegebeur, P.; Maia, W.; Charkaluk, E. Comparative study of fatigue properties of Ti-6Al-4V specimens built by electron beam melting (EBM) and selective laser melting (SLM). Mater. Charact. 2018, in press.

4. Limodin, N.; el Bartali, A.; Wang, L.; Lachambre, J.; Charkaluk, E. Application of X-ray microtomography to study the influence of the casting microstructure upon the tensile behaviour of an Al-Si alloy. Nucl. Inst. Methods Phys. Res. B 2014, 324, 57-62.

5. Wang, L.; Limodin, N.; el Bartali, A.; Witz, J.-F.; Seghir, R.; Buffière, J.-Y.; Charkaluk, E. Influence of pores on crack initiation in monotonic tensile and cyclic loadings in lost foam casting A319 alloy by using 3D in-situ analysis. Mater. Sci. Eng. A 2016, 673, 362-372.

6. Buffière, J.-Y.; Savelli, S.; Jouneau, P.H.; Maire, E.; Fougères, R. Experimental study of porosity and its relation to fatigue mechanisms of model Al-Si7-Mg0.3 cast Al alloys. Mater. Sci. Eng. A 2001, 316, 115-126.

7. Chastand, V. Etude du Comportement Mécanique et des Mécanismes D'endommagement de Pièces Métalliques Réalisées par Fabrication Additive. Ph.D. Thesis, Ecole Centrale de Lille, Villeneuve-d'Ascq, France, 2016. Available online: https://tel.archives-ouvertes.fr/tel-01484725/document (accessed on 10 November 2016). (In French)

8. Donachie, M.J. Titanium: A Technical Guide, 2nd ed.; ASM International: Materials Park, OH, USA, 2000.

9. Fatemi, A.; Molaei, R.; Sharifimehr, S.; Shamsaei, N.; Phan, N. Torsional fatigue behavior of wrought and additive manufactured Ti-6Al-4V by powder bed fusion including surface finish effect. Int. J. Fatigue 2017, 99, 187-201.

10. Fatemi, A.; Molaei, R.; Sharifimehr, S.; Phan, N.; Shamsaei, N. Multiaxial fatigue behavior of wrought and additive manufactured Ti-6Al-4V including surface finish effect. Int. J. Fatigue 2017, 100, 347-366.

11. Szmytka, F.; Limodin, N.; Wang, L.; Osmond, P.; Adrien, J.; Charkaluk, E.; Buffiere, J.Y. Probabilistic thermal-mechanical fatigue criterion for lost foam casting aluminium alloys based on 2D/3D porosities distribution. MATEC Web Conf. 2014, 12, 05005.

(C) 2018 by the authors. Licensee MDPI, Basel, Switzerland. This article is an open access article distributed under the terms and conditions of the Creative Commons Attribution (CC BY) license (http://creativecommons.org/licenses/by/4.0/). 